\title{
DESAFIOS DA SOCIEDADE DA INFORMAÇÃO NA RECUPERAÇÃO E USO DE INFORMAÇÕES EM AMBIENTES DIGITAIS
}

CHALLENGES OF THE INFORMATION SOCIETY IN RECOVERING AND USING INFORMATION IN DIGITAL ENVIRONMENTS

1Samyr Santos Delfino

2Júlio Afonso Sá de Pinho Neto

${ }^{3}$ Marckson Roberto Ferreira de Sousa

Universidade Federal da Paraíba1,2,3

\section{Correspondência}

Samyr Santos Delfino

Universidade Federal da Paraíba

João Pessoa, PB - Brasil

E-mail: samyrsd@gmail.com

(iDORCID: https://orcid.org/0000-0002-2221-3192

Sistema de Similaridade
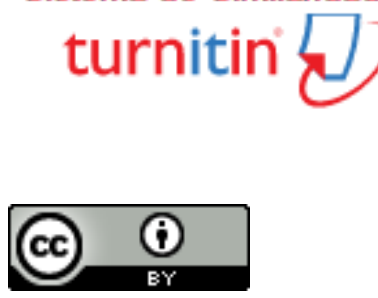

JITA: BD. Information society.

e-Location: 019036 


\section{RESUMO}

Para a sociedade contemporânea, também conhecida como sociedade da informação, a informação é considerada como sendo o seu bem de maior valor. Porém, mesmo sendo o cerne dessa nova sociedade, o grande volume de informação desencadeia uma série problemas. A liberdade na comunicação, possível através do uso da internet e das redes sociais, associadas à ausência de hierarquia na produção e disseminação na internet potencializa o surgimento de uma inundação de informações que dificultam a capacidade de análise e crítica por parte dos seus usuários. Problemas como pós-verdade, fake-news e desinformação se tornam cada vez mais comuns e despertam questionamentos referentes à qualidade dos integrantes dessa sociedade, uma vez que a formação de opinião sofre influência direta da qualidade das informações disponíveis na internet e nas redes sociais. Pensando nisso, se vê como oportuno a realização de uma pesquisa bibliográfica com a finalidade de investigar ações visando a identificação das fake-news no contexto da pós-verdade, bem como, combater a sua produção e disseminação, pois no atual momento em que a sociedade da informação se encontra, percebe-se o surgimento de potenciais problemas relacionados ao grande volume de informações disponíveis.

\section{PALAVRAS-CHAVE}

Informação, fake News, sociedade da informação.

\section{ABSTRACT}

In our contemporary society, also known as information society, information is considered to be its most valuable asset. However, even though information is in the core of this new culture, its overwhelming volume triggers several problems. Freedom in communication, possible through the use of the Internet and social networks, associated with the lack of hierarchy in the production and dissemination on the its channels, results in a flood of information that hinders the ability of analysis and criticism from its users. Problems such as posttruth, fake-news and misinformation has become increasingly common and gave rise to questions regarding the quality of the members user of this society, considering that opinions are directly influenced by the information available on the Internet and social platforms. In light of the above, and foreseeing additional potential problems directly related to the extreme volume of information available to the public, it is seems fitting (and necessary) the performing of a literature research with the purpose of mapping actions to identify the fake-news in the context of post-fact, as well as to stop its production and dissemination.

\section{KEYWORDS}

Information, fake news, information society. 


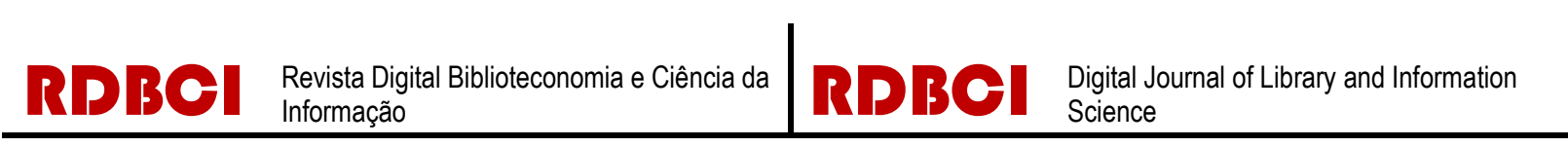
Introdução

A capacidade de analisar e criticar as informações disponíveis, afim de poder compreender o mundo ao nosso redor e com isso decidir sobre a possibilidade de fazer uso ou não dessas informações, ou simplesmente decidir se devemos compartilhar com outros integrantes da sociedade, é um desejo e uma necessidade de todos os integrantes da sociedade contemporânea também conhecida como sociedade da informação.

A presença das tecnologias, também conhecidas como tecnologias da informação e comunicação (TICs), no cotidiano dos integrantes da sociedade da informação exerce enorme influência na vida dessas pessoas, impondo mudanças impactantes nas suas relações sociais e econômicas e favorecendo o surgimento de novos hábitos que proporcionam mudanças na realização de atividades básicas do dia a dia, a exemplo do próprio processo de comunicação.

O grande número de meios de comunicação existentes possibilita a produção e disseminação de um abundante volume de informações, proporcionando uma sobrecarga de informações que resulta em diversas mudanças de comportamento dos integrantes da sociedade da informação. Associado a esse grande número de canais de comunicação ainda pode se mencionar o fato de a internet permitir uma integração em tempo real independente de questões geográficas que outrora eram entendidas como barreiras ao fluxo da informação.

Em um ambiente com elevado potencial de interação social, a produção e disseminação de informações se torna um ponto preocupante num cenário onde o mesmo usuário pode assumir tanto o papel de produtor, como o de consumidor de informações. Dessa maneira aumenta a complexidade em garantir a qualidade das informações ali compartilhadas.

Segundo Varela (2007), o grau de desenvolvimento de uma sociedade pode ser evidenciado pela qualidade de informação disponível para a sua comunidade, sendo assim informações de baixa qualidade e credibilidade, a exemplo das informações falsas, não checadas, tais como boatos, calúnias ou difamações também conhecidas como fake news se tornam um grande problema para a sociedade da informação.

O potencial destrutivo de uma informação falsa ou fake news é incalculável, isso se considerarmos o alto índice de interatividade existente entre os usuários das redes sociais, o que possibilita um alcance que pode chegar facilmente a milhões de usuários em pouco tempo. Mesmo com esse potencial destrutivo, um ponto que chama atenção está no fato de que, segundo Azzimonti e Fernandes (2018), poucos estudos estão sendo realizados com foco em avaliar como a presença das fakes news em redes e mídias sociais afetam a desinformação e polarização em uma sociedade.

Além do potencial negativo provocado pelo compartilhamento das fake news, outros problemas podem ser vinculados à produção e disseminação de um grande volume de 


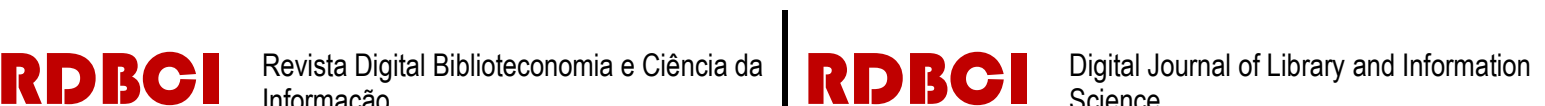

informações através das redes sociais e demais meios de compartilhamento de informações em formatos digitais. Segundo, Fontes e Gomes (2013) os integrantes da sociedade da informação vivem uma certa insatisfação constante, o que os faz estarem sempre em busca de algo novo. $\mathrm{O}$ imediatismo presente nessa sociedade fez com o que o tempo de satisfação com uma informação se torne cada vez menor, pois o número de possibilidades de novas informações estarem disponíveis aumenta a ansiedade e, com isso, a busca de uma informação satisfatória se torna interminável.

Analisando esse cenário, a área de ciência da informação propicia reflexões viáveis para elencar os principais problemas apontando também quais as possíveis soluções que podem ser tomadas a fim de mitigar essa controvérsia. Seguindo este raciocínio, verifica-se o surgimento de alguns conceitos, entre eles vale destacar o conceito da pós-verdade, incorporado em 2016 ao dicionário de Oxford que apresentou a seguinte definição:

Relacionando ou denotando circunstâncias em que fatos objetivos são menos influentes na formação da opinião pública do que apelos à emoção e crença pessoal. (OXFORD, 2016)

Já no que se refere a possíveis soluções, identifica-se algumas ações realizadas no âmbito da educação, bem como na área jurídica através da criação de leis que objetivem a regulamentação da criação e disseminação dessas informações na tentativa de responsabilizar seus autores de possíveis danos que possam vir a ocorrer.

Diante do exposto, é bastante oportuno realizar um estudo bibliográfico que objetive o levantamento de informações referentes às práticas nas áreas da ciência da informação, educação e ciências jurídicas, afim de definir um conjunto de ações que possam ser implementadas para uma melhor compreensão de acesso e uso das informações digitais que são compartilhadas na internet, na busca do combate as fake news, pós-verdades e desinformação.

Neste sentido o referido artigo subdivide-se em quatro tópicos, sendo o primeiro tópico a busca pela compreensão e entendimento sobre os conceitos associados à criação do termo "sociedade da informação", o segundo tópico é relacionado aos problemas identificados nas informações digitais compartilhadas na internet, através da compreensão dos conceitos associados à zumbificação "que consiste no impacto que o consumo de informações falsas provoca nos integrantes de uma sociedade" da informação e pós-verdade. Já no terceiro tópico serão explorados estudos relacionados às boas práticas de acesso e uso da informação digital no ambiente educacional, bem como as iniciativas jurídicas realizadas com o objetivo de normatizar e responsabilizar os autores das fake news. Por fim, no quarto tópico serão apresentadas as considerações finais contendo observações sobre os problemas e ações para a solução destas questões, de melhorias identificados ao longo do artigo. 


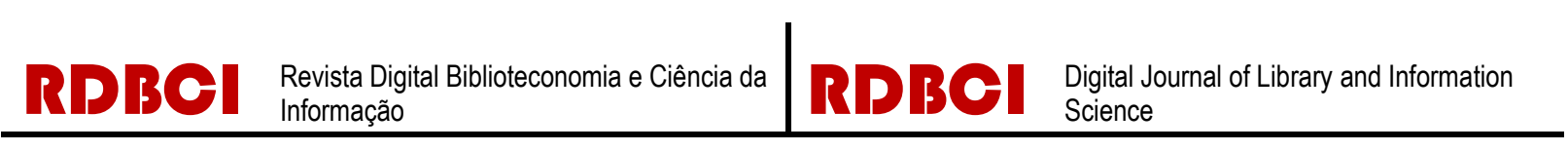

\section{Sociedade da Informação}

Para Oliveira (2012), a inovação constitui uma característica fundamental ao ser humano em sua busca pela sobrevivência. Essa deve ser umas das características mais marcantes da sociedade contemporânea devido à forte presença dos recursos tecnológicos que estão em todos os segmentos da sociedade.

A presença da tecnologia da informação (TI) pode ser percebida a todo momento e em todos os lugares. Atividades simples como, por exemplo, a realização de uma conversa face a face está sendo substituída por diálogos realizados por aplicativos de mensagens instantâneas, o que muda completamente a forma como a informação é gerada, armazenada e compartilhada.

A influência da tecnologia sobre o comportamento da sociedade teve seu início logo após a segunda guerra mundial, na terceira revolução industrial, marcada pelo crescente uso de recursos da informática nos processos de produção. Porém, com a criação e popularização da internet a globalização surgiu como sendo um processo que estabelece a integração econômica, social e cultural entre mercados e pessoas nos diversos países do mundo, foi que essa influência ganhou força e, de fato, mudou (e ainda vem mudando) os hábitos da sociedade contemporânea.

A influência tecnológica, acima mencionada, propicia a criação de um cenário de migração de um mundo tradicional para um mundo digital, onde o uso das tecnologias supera hábitos tradicionais. Um exemplo dessa mudança pode ser visto no processo da comunicação, como por exemplo a comunicação realizada através de meio eletrônico, opção esta preferida pela população. A escolha pelos recursos eletrônicos se justifica por vários motivos, porém a agilidade e a praticidade são os mais significativos. Nesse sentido, de acordo com Le Coadic (2004), é correto afirmar que os sistemas eletrônicos encurtam o tempo de execução das tarefas de busca e processamento das informações.

Os avanços tecnológicos exerceram forte influência em diversas mudanças organizacionais, técnicas e administrativas, possibilitando à informação o status de bem de maior valor para a sociedade e com isso criando a sociedade da informação.

O conceito de sociedade da informação, que de acordo com Werthein (2000), passou a ser utilizado no início do século XXI como substituto para o conceito complexo de "sociedade pós-industrial" refere-se a uma sociedade "informacional" influenciada pelo surgimento de novas tecnologias com maior ênfase na flexibilidade, agilidade e mobilidade das informações produzidas, consumidas e compartilhadas por todos os integrantes dessa sociedade.

Segundo Castells (1999, citado por Werthein, 2000), as transformações em direção à sociedade da informação possuem algumas características fundamentais, sendo elas: 


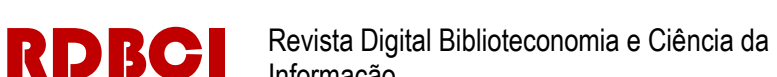

- A informação como sendo sua matéria prima - a informação passa a ser o centro das atenções, ao contrário do passado quando a tecnologia passava a ser apenas um insumo na busca de melhorias na tecnologia.

- Alta penetrabilidade das tecnologias na sociedade contemporânea - a informação passa a ser parte integrante de toda a atividade humana, individual ou coletiva com isso essas atividades passam a sofrer influência direta da tecnologia.

- Preferência pela lógica de redes - a possibilidade das novas tecnologias serem implementadas em qualquer tipo de processo.

- Flexibilidade - o uso da tecnologia permite a reversão, modificação e reorganização de processos, seguindo o conceito da modernidade líquida, definido por Bauman (2001).

- Convergência tecnológica - trajetórias de desenvolvimento tecnológico em diversas áreas do conhecimento interligadas.

Corroborando com esse entendimento, Fontes e Gomes (2013) afirmam que o surgimento e popularização da internet, que avança e se renova diariamente, pode ser entendido como responsável pelos processos de reconfiguração de práticas sociais e culturais na sociedade da informação. A escolha da internet para viabilizar o processo de comunicação fez surgir a opção pelo imediatismo, que no cenário das TICs pode ser representado pela agilidade e mobilidade. Esses conceitos remetem à ideia de adaptabilidade, onde a informação se torna disponível independentemente da sua forma, alinhado com o conceito de "modernidade líquida" definido por Bauman (2001), que faz uma alusão à flexibilidade e à capacidade de adaptação as frequentes mudanças que essa sociedade venha a sofrer.

Além da necessidade de adaptabilidade a novas formas de comunicação e interação social, os integrantes da sociedade da informação também se veem obrigados a enfrentar outros desafios relacionados ao grande volume de informação a que estão expostos diariamente, a exemplo da incapacidade de analisar e diferenciar, com clareza e reflexão o imenso volume de informações a que estão expostos frequentemente, o que pode ser definido, segundo alguns autores Oxford (2016) e Leite e Matos (2017) como pós-verdade, desinformação ou apenas fake news".

\section{Zumbificação da Informação Através do Conceito de Pós-Verdade}

Zumbificação é um conceito atual, criado para exemplificar o impacto que o consumo de informações falsas ou sem credibilidade nos integrantes da sociedade da informação.

Conforme Leite e Matos (2017), a definição de zumbificação se refere:

ao processo de disseminar e consumir informação falsa ou distorcida sem perceber, devido à ausência de interpretação crítica e checagem de fontes, contribuindo para a infecção generalizada da desinformação na internet. (LEITE e MATOS, 2017)

\begin{tabular}{l|l|l|l|l|l|}
\hline (c) RDBCl: Rev. Digit. Bibliotecon. Cienc. Inf. & Campinas, SP & v.17 & $1-16$ & e019036 & 2019 \\
\hline
\end{tabular}




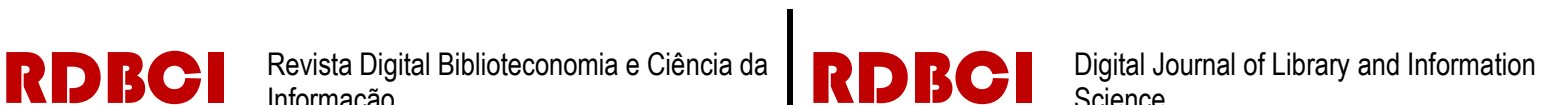

Esse conceito está muito alinhado com o cenário vivido pelos integrantes da sociedade da informação. Ambientes com abundância de informação e baixo índice de hierarquia no processo de produção, avaliação e disseminação dessas informações é propicio ao surgimento de informações com baixa credibilidade atualmente conhecidas como pós-verdade, desinformação ou fake news.

É bem verdade que esse tipo de informação já existia, anteriormente conhecida como calúnia, mentira, entre outros termos frequentemente utilizados antes da popularização da internet e das redes sociais. Também é verdade que o surgimento e popularização da internet, e demais recursos de fluxo de dados a exemplo das redes sociais, elevaram em muito a incidência de produção e compartilhamento de informações falsas, chegando a um patamar em que, de acordo com Leite e Matos (2017), o número de informações falsas disseminadas na internet chega a ser superior ao número de informações verdadeiras.

Nesse sentido, é oportuno destacar que, segundo Alonso Muñoz e Casero Ripolles (2018), um dos fatores que podem influenciar para que uma mensagem se torne viral é o seu conteúdo, importando mais, inclusive, do que a fonte de onde essa informação foi gerada.

Essa realidade dificulta bastante a capacidade de analisar e criticar as informações, em especial no que concerne ao julgamento para definir se determinada informação é legítima e verdadeira ou não. Tal dificuldade dispara o alerta sobre a qualidade das opiniões que estão sendo formadas atualmente, uma vez que essas opiniões, provavelmente, podem ter como base informações falsas que não foram originadas de fontes confiáveis.

A contribuição da Ciência da Informação para os avanços nos estudos de combate à zumbificação na internet fica evidente quando se percebe que o cerne do problema em questão está na informação em si. Vale ressaltar que a produção, disseminação, acesso e uso da informação já são objetos de estudo da Ciência da Informação.

Outro ponto de destaque está no fato da Ciência da Informação ser entendida como uma área multidisciplinar o que favorece os estudos dessa natureza devido à necessidade de compreensão de elementos bem diversificados tais como estudos cognitivos e elementos tecnológicos, a exemplo de dispositivos moveis que permitem maior agilidade no acesso e uso de informações digitais, necessários para a compreensão do ambiente digital que essas informações estão sendo divulgadas.

\section{Pós-Verdade}

A utilização do termo pós-verdade não é recente, já que de acordo com o Dicionário Oxford (2016) o termo foi empregado pela primeira vez, em 1992, por Steve Tesich, que escreveu sobre os escândalos do caso Irã e a Guerra do Golfo. 


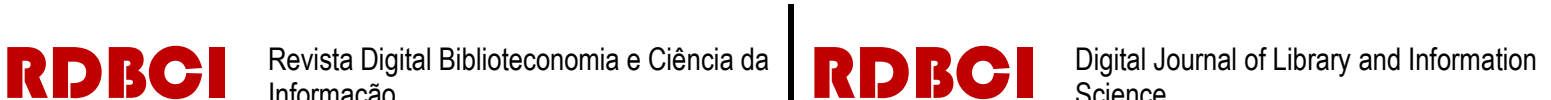

A Pós-verdade ganhou visibilidade em 2016 devido ao grande volume de informações produzidas e compartilhadas via web relacionadas à eleição presidencial americana e a saída do Reino Unido da União Europeia (Brexit). Nesse ano a palavra pós-verdade foi eleita a palavra do ano, segundo Dicionário de Oxford (2016).

Ainda em 2016, o Dicionário de Oxford incorporou o termo à sua publicação como sendo um adjetivo com a seguinte definição: "Relacionando ou denotando circunstâncias em que fatos objetivos são menos influentes na formação da opinião pública do que apelos à emoção e crença pessoal".

Outras definições ou associações ao termo pós-verdade surgiram nessa época, a exemplo de termos como informações não checadas, boatos, calúnias e difamações. No meio digital a pós-verdade ficou ainda mais conhecida pelo termo fake news que significa notícias falsas.

Segundo Monteiro (2016) citado por Silva, Luce e Filho (2017) considerando a presença maciça de relatos de pós-verdade relacionados a itens políticos, é sugerido o surgimento de uma pós-verdade política, descrita como:

\begin{abstract}
parte do processo de disseminação acelerada/amplificada de dados gerados em Tecnologias de Informação/Comunicação - TICs, diante da rápida divulgação, em que é inevitável surjam infindas versões sobre fatos, o que seria importante/relevante se eliminasse absurdos das dicotomias, porém as verificações cada vez mais complexas, diversas, diversificadas... geraram essa face obscura, 'policotomicas' /'multicotomicas' o lado B, o dark side de realidades; - dessa maneira, especialistas em informações enviesadas/distorcidas/boatos/fofocas... (spin doctors - produtores de factoides) aproveitam-se de incertezas/inseguranças provocadas na quebra de dicotomias a criar pós-verdades, novas verdades, pseudoverdades, meias verdades... apoiadas em indícios/convicções, já que fatos tornaram-se híbridos/complexos à verificação. (MONTEIRO, 2016).
\end{abstract}

Ainda sobre a compreensão referente à pós-verdade, Keyes (2004) sugere a presença de um terceiro elemento no contexto informacional, onde existem informações que não podem ser classificadas como completamente verdades nem como completamente mentiras. Nesse sentido, Higgins (2016) apresenta uma visão relativista sobre a pós-verdade onde a compreensão pode variar de pessoa para pessoa, abrindo, dessa forma, um outro questionamento: o que seria verdade?

A compreensão/definição sobre o que é ou não verdade é um tema de estudo muito recente que, segundo Silva, Luce e Filho (2017), existem poucos estudos realizados dentro da Academia, tendo como um fator complicador a velocidade de produção e disseminação através das mídias sociais.

Mesmo se tratando de um tema recente, com poucas referências acadêmicas, é possível identificar trabalhos que apontam formas de averiguação de conteúdos

\begin{tabular}{l|l|l|l|l|l|}
\hline (c) RDBCl: Rev. Digit. Bibliotecon. Cienc. Inf. & Campinas, SP & v.17 & $1-16$ & e019036 & 2019 \\
\hline
\end{tabular}




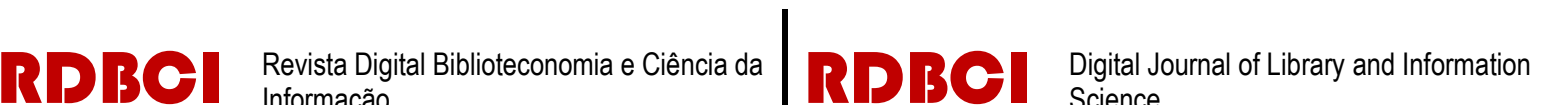

informacionais on-line. A exemplo de Tomáel et al. (2001), que ressalta a consistência e a confiabilidade da informação como formas de averiguação da veracidade da mesma. A primeira faz referência ao conteúdo da informação, ou seja, se os dados apresentados são coerentes, já a segunda analisa a credibilidade da fonte que a elaborou.

As incertezas relacionadas à pós-verdade, em especial na dificuldade em definir o que é verdade e o que é mentira, associado ao crescente uso de mídias sociais por grande parte da sociedade contemporânea impulsionou sobremaneira a criação e compartilhamento das informações espontâneas.

As informações espontâneas surgem através de um processo sem hierarquia, onde a liberdade de produção proporciona a criação de informações com base em opiniões, inverdades e "verdades próprias", que são criadas por qualquer pessoa e que são compartilhadas como sendo verdades absolutas por intermédio das mídias sociais. Segundo Marteleto (2001), esse fenômeno pode ser chamado como a "Era da Pós-Verdade".

O termo "era da pós-verdade", surgiu com a expansão do acesso à informação através da popularização do uso Internet, em especial via mídias sociais, principalmente no Facebook, Twitter, YouTube e WhatsApp que têm um vasto alcance e penetração no usuário comum da Internet.

A existência da pós-verdade não está relacionada ao crescimento e popularização da tecnologia, em especial a internet e as redes sociais. Porém, fica evidente que o uso desses recursos tecnológicos potencializa os impactos proporcionados pela criação e compartilhamento dessas informações.

Os estudos sobre os impactos e ações de combate à zumbificação, fake news e pósverdade na internet é complexo e essa complexidade fica ainda mais evidente quando se analisam as possíveis motivações que levam um usuário a produzir ou disseminar uma informação falsa, pois essa prática pode ser fruto apenas do seu desconhecimento ou até mesmo uma atitude intencional com o objetivo de causar a desinformação motivada por alguma demanda ilícita.

Pensar na prevenção e combate a essa realidade vai muito além de pensar apenas nas questões relacionadas às motivações, sejam elas intencionais ou não, que levam um usuário a produzir e disseminar essas informações na internet. É preciso buscar o entendimento referente aos motivos que levam os usuários preferirem informações sem credibilidade em detrimento das informações originadas de fontes confiáveis. 


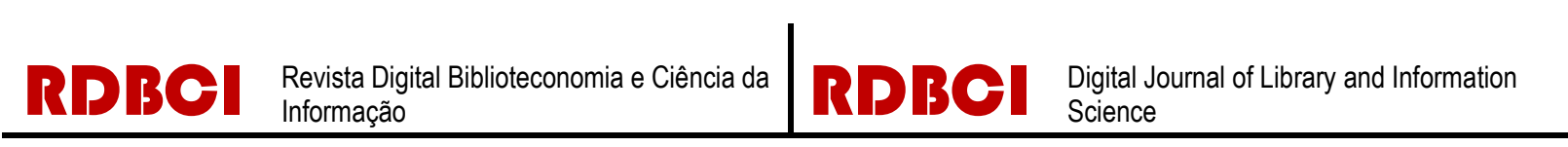
Conscientização do Uso da Informação Digital

Ao se falar em ações relacionadas à cultura digital, conscientização para o uso de informações digitais ou apenas informações digitais, possivelmente a primeira reflexão que se faz está relacionada às atividades de fomento à inclusão digital. Ações que beneficiem a inclusão digital são benéficas, em um primeiro momento, para o favorecimento de uma cultura de inclusão social, porém se mal elaboradas, podem potencializar os impactos gerados pela criação, disseminação, acesso e uso de informações falsas.

Em um cenário globalizado, onde a sociedade contemporânea é reconhecida como a sociedade da informação devido à uma forte influência surgida com a presença da tecnologia. Não ser incluído digitalmente remete a uma exclusão social, essa afirmação ganha veracidade quando reconhecemos que várias práticas sociais sofreram alterações com a inclusão da tecnologia no cotidiano da sociedade da informação.

Segundo Silva (2005), a inclusão digital é um tema de grande interesse social e econômico, por esse motivo o governo investe no desenvolvimento de várias ações de fomento seguindo a premissa de que sem "cidadãos digitais" não há "governo eletrônico". Esse interesse consiste inicialmente na justificativa de proporcionar melhorias na qualidade de vida dos incluídos digitalmente, porém fica evidente que essas ações favorecem o aumento das relações comerciais, visto que transações comerciais eletrônicas aumentam significativamente, uma vez que mais indivíduos passam a ser incluídos no universo digital.

Já no que tange às questões relacionadas à qualidade da informação digital, objeto central desse trabalho, ações de inclusão digital com foco único e exclusivo na inserção de integrantes da sociedade nos meios digitais de comunicação e interação, representam risco ao aumento da produção de informações falsas, independente da motivação e com isso favorecendo ao aumento de usuários adeptos a pós-verdade. Como forma de combate a esse problema, se faz necessário o desenvolvimento de ações relacionadas ao uso consciente da informação digital, proporcionando dessa forma o surgimento de usuários conscientes, que tenham como preocupação fundamental, priorizar a informação confiável para o desenvolvimento de um conhecimento de qualidade.

Diante da complexidade existente para o desenvolvimento de estudos relacionados ao tema de acesso e uso de informações digitais de forma consciente, percebe-se a contribuição que a área da Ciência da Informação pode disponibilizar, não apenas pelo fato de ter a informação como sendo o cerne de seu objeto de estudo, mas a sua característica de multidisciplinaridade permite à CI tecer um diálogo eficiente com outras áreas de estudo a exemplo das áreas de TIC e educação. 


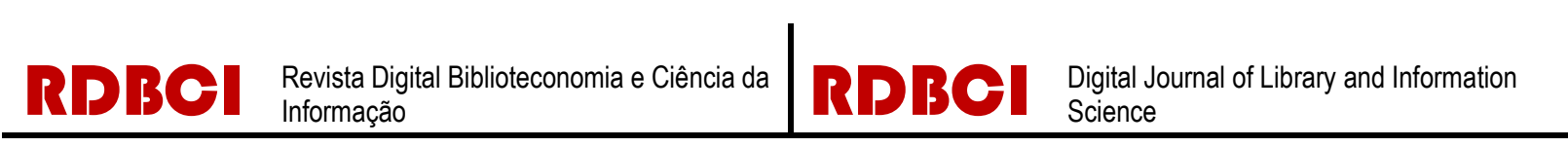

Educação Para Competência Informacional

O movimento da educação para informação digital teve como marco principal o final do século XX através de uma mobilização mundial em prol da inserção da sociedade nesse novo contexto de sociedade da informação. Ao longo desse período diversas iniciativas foram realizadas em vários países a fim de construir políticas nacionais que objetivem a construção de programas capazes de fazer com que a sociedade adquira, de fato, o status de "sociedade da informação".

No Brasil, segundo Silva (2005), esse esforço resultou na publicação do Livro Verde da Sociedade da Informação (SOCIEDADE, 2000). Ainda segundo o autor, a publicação traz o conceito de alfabetização digital que consiste na formação de cidadãos não apenas habilitados a lidar com recursos tecnológicos, mas também dotados de conhecimento na utilização de plataformas digitais em favor de interesses pessoais e coletivos.

De acordo com Sociedade (2000), a educação pode ser vista como um fator determinante para a desigualdade social. Nesse sentido o referido autor afirma que:

A educação é o elemento-chave na construção de uma sociedade baseada na
informação, no conhecimento e no aprendizado. Parte considerável do desnível
entre indivíduos, organizações, regiões e países deve-se à desigualdade de
oportunidades relativas ao desenvolvimento da capacidade de aprender e concretizar
inovações. (SOCIEDADE, 2000)

Ainda sobre a alfabetização digital, fica evidente que para sua viabilização se faz necessário que o cidadão possua a capacidade de realizar a recuperação de informações digitais disponíveis na internet. Nesse sentido Le Coadic (2004) contribui com a seguinte comentário:

O montante de informações na Internet leva a que se proponham questões sobre habilidades necessárias para aprender a se informar e aprender a informar, sobre onde adquirir informação é alerta sobre a ausência dessa aprendizagem no sistema de ensino. (LE COADIC, 2004).

A contribuição de Le Coadic (2004) traz à baila o impacto do volume de informação digital disponível na Internet e inexistência desse tema como objeto de estudo no âmbito da educação. Tal contribuição permite que seja evidenciada a necessidade de se realizar uma reformulação nas bases da educação para sociedade da informação, o que já conceituado como sendo uma "alfabetização digital", contemplando um melhor entendimento de elementos impactados pela produção excessiva de informações e seus impactos para a sociedade.

Além da questão da educação, iniciativas no âmbito legal também podem ser vistas como importantes no combate à produção e proliferação das fake news e na seleção mais 


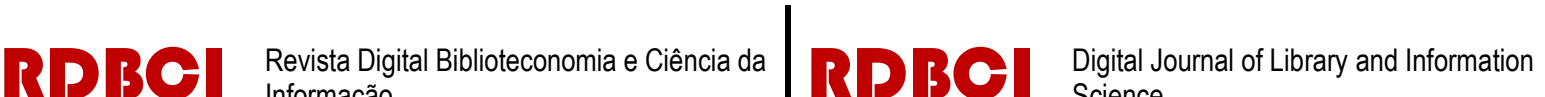

eficiente de informações, com a priorização da escolha de informações com base em fontes mais confiáveis. Nesse sentido se vê como oportuno o estudo das legislações criadas com o intuito de regulamentar a produção e disseminação de informações em ambientes digitais. A exemplo da internet e das redes sociais.

\section{Regulamentação Para Acesso e Uso da Informações em Ambientes Digitais}

No âmbito legal, no que se refere ao uso consciente e responsável das informações disponibilizadas na internet e nas redes sociais e regulamentações que preveem punições para transgressores, destacam-se o Marco Civil da Internet, também conhecido como Lei $\mathrm{n}^{\circ} 12.965 / 2014$ e a Lei Geral de Proteção de Dados (LGPD), também conhecida como Lei $\mathrm{n}^{\circ}$ $13.709 / 2018$.

O projeto do Marco Civil da Internet surgiu em 2009, porém foi aprovado apenas em 2014. Segundo Brasil (2014), o Marco Civil da Internet estabelece princípios, garantias, direitos e deveres para o uso da internet no Brasil e determina as diretrizes para atuação da União, dos Estados, do Distrito Federal e dos Municípios.

A proposta do Marco Civil da Internet consiste em abordar temas como neutralidade da rede, privacidade e retenção de dados. Além disso outros pontos contemplados relacionam-se com a função social da internet no que se refere à garantia da liberdade de expressão e a transmissão de conhecimento e da definição das obrigações de responsabilidade dos usuários e provedores.

Referente a LGPD, sua aprovação teve influência direta com os eventos relacionados a escândalos de segurança de dados que resultaram no vazamento de informações que exerceram influência em eventos como eleições presidências, além de vendas de grandes massas de dados contendo informações sigilosas de usuários.

Neste sentido, conforme a Brasil (2018):

Esta Lei dispõe sobre o tratamento de dados pessoais, inclusive nos meios digitais, por pessoa natural ou por pessoa jurídica de direito público ou privado, com o objetivo de proteger os direitos fundamentais de liberdade e de privacidade e o livre desenvolvimento da personalidade da pessoa natural. (BRASIL, 2018).

No artigo $2^{\circ}$ da referida Lei, a disciplina da proteção de dados pessoais tem como fundamentos, entre outros, destaca-se o respeito a privacidade e a inviolabilidade da intimidade, da honra e da imagem. Esses tópicos estão estreitamente relacionados com a necessidade e o desejo de regulamentar e punir a prática de produção e disseminação de fake news e da desinformação proposital independente da sua motivação. 


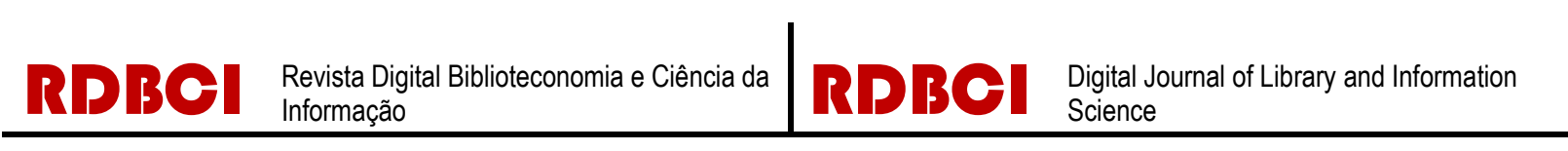

\section{Considerações Finais}

A presença das TICs no cotidiano da vida em sociedade é uma realidade que não tem como retroceder, ao contrário, o que se espera para um futuro próximo é que essa relação homem-máquina fique ainda mais próxima, chegando ao ponto de se confundir em determinados contextos.

Nesse cenário se vê como de extrema relevância a atuação da área de Ciência da Informação com estudos nas subáreas de arquitetura da informação, estudos de usuários e arquitetura da informação pervasiva que objetivem o desenvolvimento de melhorias nessa relação, possibilitando o desenvolvimento de recursos para uma melhor recuperação, acesso e uso das informações disponibilizadas e compartilhadas na internet e nas redes sociais.

Referente às ações na área da educação, fica evidente uma lacuna que precisa ser preenchida nas políticas educacionais que objetivem uma maior compreensão, reflexão e senso crítico por parte da sociedade referente à seleção das informações que servirão de base para formação de opiniões desses cidadãos. É válido destacar que essas ações, quando bem elaboradas e implementadas, possuem um grande potencial para oferecer à sociedade resultados positivos que podem ser percebidos através da redução do número de informações falsas disponibilizadas na internet e nas redes sociais.

Ainda sobre as ações referente à área da educação, um questionamento fica em aberto podendo servir de base no desenvolvimento de trabalhos futuros: qual o momento que se deve inserir estudos sobre uso consciente de recursos tecnológicos na vida acadêmica de um cidadão? A importância desse questionamento fica evidente quando reconhecemos que o contato com recursos de TICs vem ocorrendo cada dia mais cedo.

No âmbito da legislação, a criação do Marco Civil da Internet e da Lei Geral de Proteção de Dados podem ser reconhecidos como importantes avanços na busca pela utilização de uma internet mais consciente, porém, considerando o seu pouco tempo de criação, não foi possível ainda identificar resultados, contudo, espera-se que estes sejam identificados em um futuro próximo.

Além das ações mencionadas nesse trabalho, diversas outras vêm sendo realizadas com intuito de combater o aumento das fake news na internet e nas redes sociais, através do uso de tecnologias desenvolvidas por empresas de TIC. Um bom exemplo disso é a utilização de redes neurais pelo Facebook, o que demonstra um claro investimento na Inteligência Artificial com o intuito de analisar trilhões de posts compartilhados. O objetivo é identificar as fake news e com isso evitar que ocorra o seu compartilhamento em decorrência da falta de conhecimento do usuário a esse respeito.

A ação conjunta de toda a sociedade e do governo, para o desenvolvimento de ações no âmbito da educação, tecnologia, políticas sociais e medidas regulamentadoras, pode ser

\begin{tabular}{l|l|l|l|l|l|l}
\hline (c) RDBCl: Rev. Digit. Bibliotecon. Cienc. Inf. & Campinas, SP & v.17 & $1-16$ & e019036 & 2019 \\
\hline
\end{tabular}




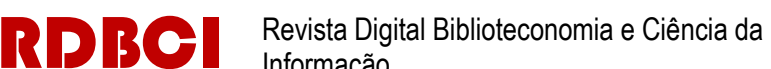

vista como excelente indicativo do desejo da sociedade em combater o uso irracional dos recursos da internet e das redes sociais, isso mostra que a ideia de que a internet é uma "terra sem leis" não está sendo mais aceita.

A velocidade com que a tecnologia avança se torna um agravante na busca por esse controle, porém como mencionado por Castells (2005):

A internet é um instrumento que desenvolve, mas que não muda os comportamentos; ao contrário, os comportamentos apropriam-se da internet, amplificam-se e potencializam-se a partir do que são. (CASTELLS, 2005, p. 273)

A ideia de manter o foco no usuário para o desenvolvimento de ações de combate às fake news, desinformação e pós-verdade se fortalecem como sendo o melhor caminho a seguir, pois os problemas são gerados devido ao comportamento dos usuários e será através de melhorias nesse comportamento que serão identificadas e aplicadas as soluções.

\section{Referências}

AZZIMONTI, M., FERNANDES, M. (2018). Redes de mídia social, notícias falsas e polarização. Disponível em: https://ideas.repec.org/p/nbr/nberwo/24462.html Acesso em 04 nov. 2019.

BAUMAN, Zygmunt. Modernidade líquida. Rio de Janeiro: Jorge Zahar Ed., 2001.

BRASIL. Lei $\mathrm{N}^{\circ}$ 12.965, de 23 de Abril de 2014. Marco civil da internet. Disponível em: http://www.planalto.gov.br/ccivil_03/_ato2011-2014/2014/lei/112965.htm. Acesso em 10 fev. 2019.

BRASIL, Lei N $\mathrm{N}^{\mathrm{1}}$ 13.709, de 14 de Agosto de 2018. Lei geral de proteção aos dados. Disponível em: http://www.planalto.gov.br/ccivil_03/_Ato2015-2018/2018/Lei/L13709.htm Acesso em 05 fev. 2019.

CASTELLS, Manuel. A era da informação: economia, sociedade e cultura. In: A Sociedade em rede, Rodrigo G. de Azevedo. São Paulo: Paz e Terra, 1999. v. 1.

CASTELLS, Manuel. Internet e sociedade em rede. In: MORAES, D. (Org.). Por uma outra comunicação: mídia, mundialização cultural e poder. 3. ed. Rio de Janeiro: Record, 2005.

FONTES, Gabriela Scroczynski, GOMES, Icléia Rodrigues de Lima Cibercidades: as tecnologias de comunicação e a reconfiguração de práticas sociais. Inf. \& Inf., Londrina, v. 18 , n. 2 , p. $60-76$, maio/ago. 2013. 


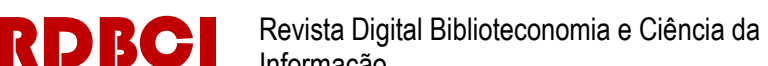

HIGGINS, K.; Post-truth: a guide for the perplexed. Nature, Londres, v. 540, n.9. 2106. Disponível em: http://www.nature.com/news/post-truth-a-guide-for-the-perplexed-1.21054. Acesso em: 19 fev. 2019

KEYES, R.; The Post-Truth ERA: dishonesty and deception in contemporary life. New York: St. Martin's Press, 2004.

LE COADIC, Yves-François. A ciência da informação. Brasília: Briquet de Lemos, 2004.

LEITE, Leonardo Ripoll Tavares, MATOS, José Claudio Morelli. Zumbificação da informação: A desinformação e o caos informacional. Revista Brasileira de

Biblioteconomia e Documentação - v. 13, n. esp. CBBD 2017.

MARTELETO, R. M.; Análise de redes sociais- aplicação nos estudos de transferências da informação. Ciência da Informação, Brasília, DF, v.30, n.1, p.71-81, 2001.

MONTEIRO A. F.; Comunicação hi-tech: digital e pós-verdade política. In: PENSACOM BRASIL - GT5 Comunicação e Política, 1, São Paulo - SP, 2016.

MUÑOZ, A., L., RIPOLLES, C,. A. Comunicação dos líderes populistas europeus no Twitter: Configuração da agenda e o efeito 'mais é menos'. El Profesional de La Información, 27 (6). doi: 10.3145 / epi. 2018.

OLIVEIRA, C. B; Uma proposta de arquitetura da informação para o processo de inovação em centros de pesquisas. Tese (doutorado) - Universidade de Brasília, Faculdade de Ciências da Informação, Programa de Pós-Graduação em Ciências da Informação (PPGCINF) - Brasília, 2012.

OXFORD DICTIONARIES. Oxford dictionaries word of the year 2016. Londres, 2016. Disponível em: https://www.oxforddictionaries.com/press/news/2016/12/11/WOTY-16. Acesso em: 19 fev. 2019.

SILVA, Helena et al. Inclusão digital e educação para a competência informacional: uma questão de ética e cidadania. Ci. Inf., Brasília, v. 34, n. 1, p.28-36, jan./abr. 2005

SILVA, L. M.; LUCE, B.; FILHO, R. S.; Impacto da pós-verdade em fontes de informação para a saúde. Revista Brasileira de Biblioteconomia e Documentação - v. 13, n. esp. CBBD 2017.

Sociedade da informação no Brasil: livro verde / organizado por Tadao Takahashi. Brasília: Ministério da Ciência e Tecnologia, 2000.

TOMAÉL, Maria Inês et al. Avaliação de fontes de informação na Internet: critérios de qualidade. Informação \& Sociedade, João Pessoa, v.11, n. 2, p. 13-35, 2001.

\begin{tabular}{ll|l|l|l|l|l|}
\hline (c) RDBCl: Rev. Digit. Bibliotecon. Cienc. Inf. & Campinas, SP & v.17 & $1-16$ & e019036 & 2019 \\
\hline
\end{tabular}


VARELA, Aida. Informação e construção da cidadania. Brasília, DF: Thesaurus, 2007.

ZUCKERBERG, Mark. Conversation with Mark Zuckberg, 2016. Techonomy. Disponível em: http://techonomy.com/conf/te16/videos-conversationswith-2/in-conversation-with-markzuckerberg/. Acesso em 20 fev. 2019

WERTHEIN, Jorge. Ci. Inf., Brasília, v. 29, n. 2, p. 71-77, maio/ago. 2000

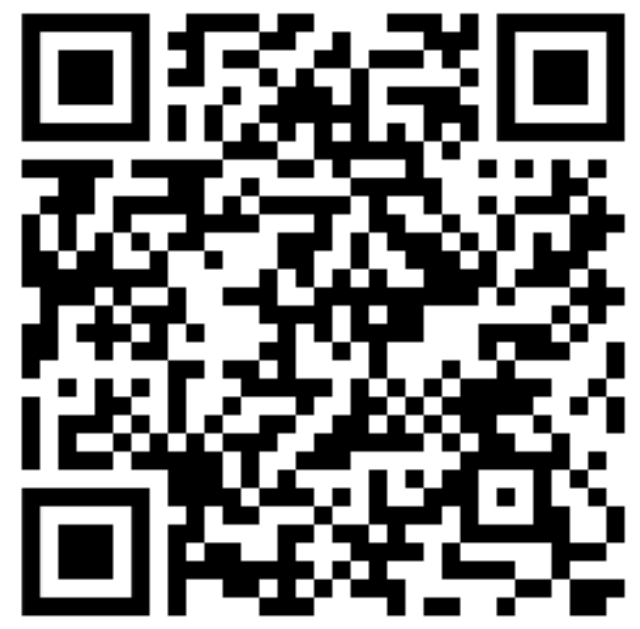

